\title{
Zoológico de Cali
}

Por: Ingrid Pineda*

Es un importante centro de conservación de especies en peligro de extinción, en el se encuentra gran cantidad de fauna perteneciente a nuestro continente y algunas otras traídas del África. Los animales se encuentran agrupados y distribuidos de acuerdo al grupo taxonómico en el que se ubican; es decir encontraremos en lugares diferentes a los primates, reptiles y anfibios, aves, felinos, algunos otros mamíferos.

La variedad de formas, colores y conductas de los animales, han hecho de este lugar un importante centro educativo, tanto de diversión para adultos y niños.

Está catalogado como uno de los mejores zoológicos de Latinoamérica.

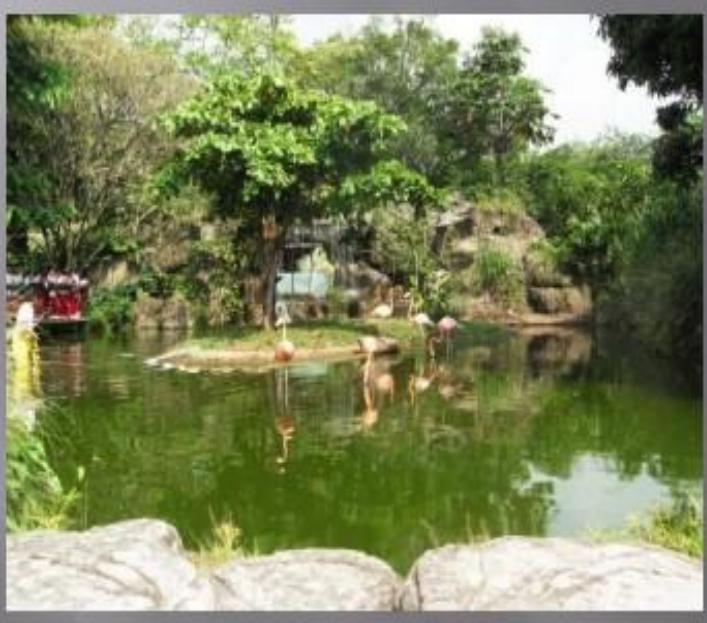

Rey de los gallinazos (Sarcoramphus papa) es principalmente de vida solitaria.
En la entrada el lago principal nos muestra el hermoso e imponente Flamenco rosado (Phoenicopterus ruber).

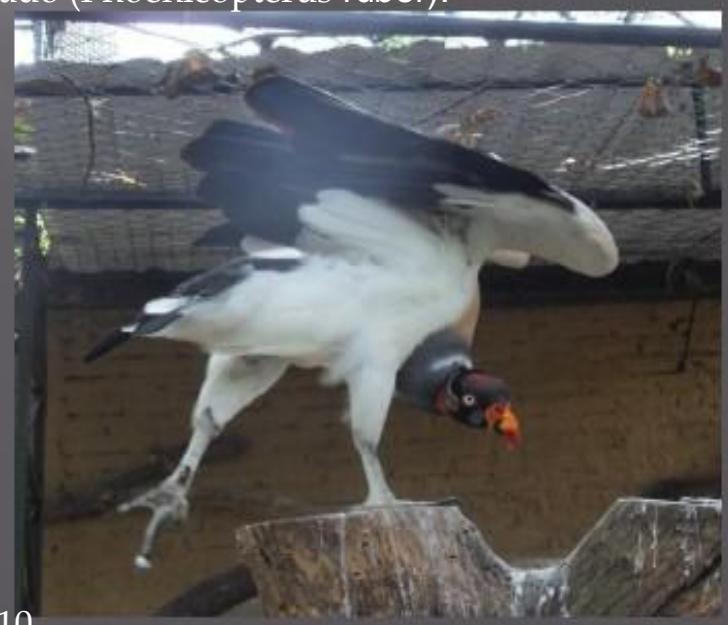

*Estudiante de Octavo Semestre. Universidad Pedagógica Nacional. 2010. 


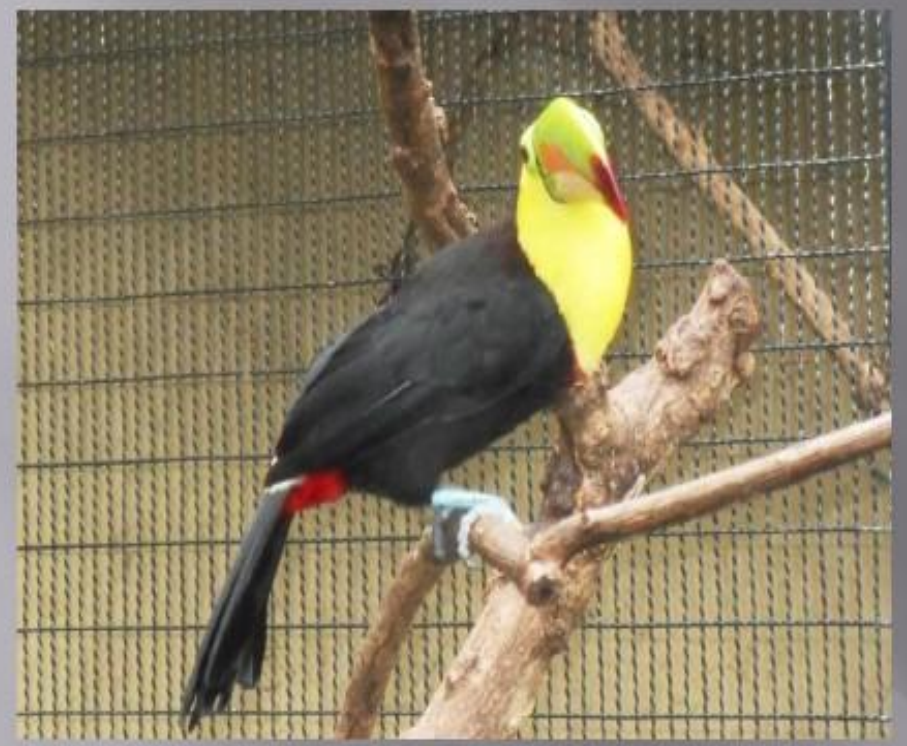

Tucán (Ramphastos sp) en todas las especies se destaca el gran tamaño de su pico, además de su vistoso color .

Guacamayos (Ara spp) se puede encontrar gran cantidad de especies de estas aves, presentan colores bastante vistosos en su plumaje.

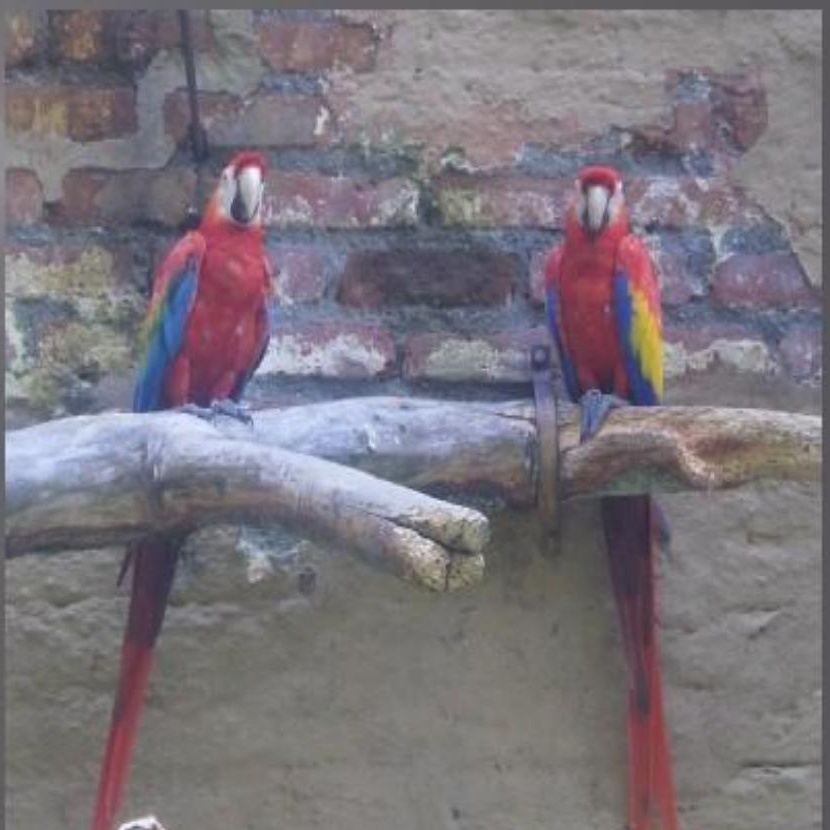



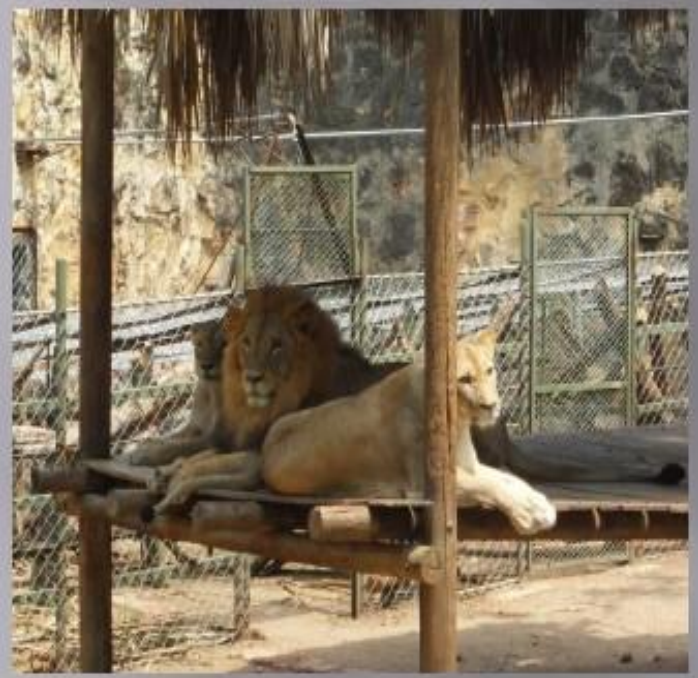

ElimponenteLeónAfricano

(Panthera leo), con elJaguar

(Panthera onca) son unos de los animales más observados.; debido a que son considerados unos de los felinos mas temidos del planeta.
El papión (Papio hamadryas) es otro primateproveniente del antiguo mundo, lastimosamente ya no existen poblaciones en su ambiente natural.

Dentro de los primates encontramos el Mono aullador rojo (Alouatta seniculus) es uno de los animales que produce uno de los sonidos más fuertes en la naturaleza.

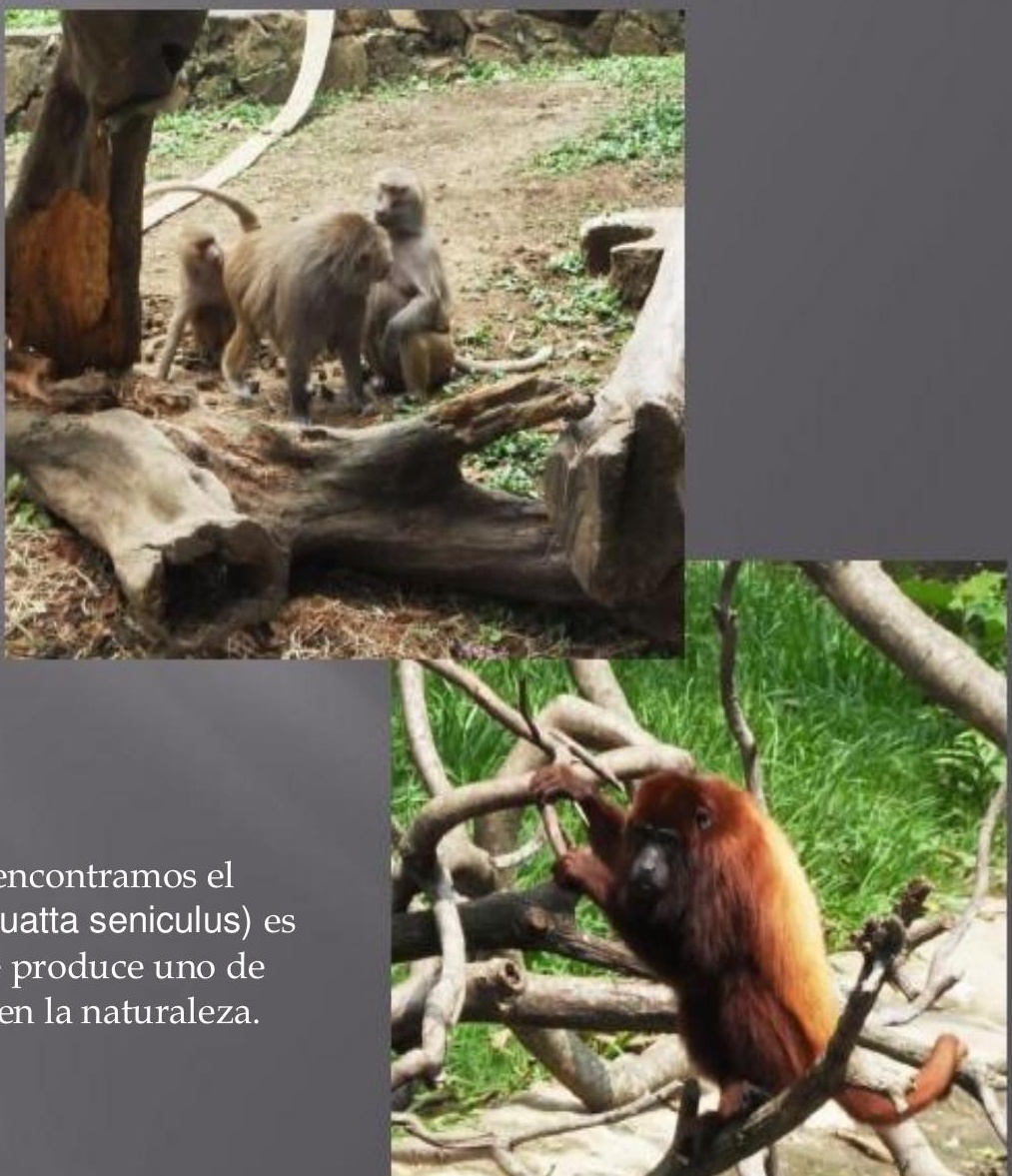



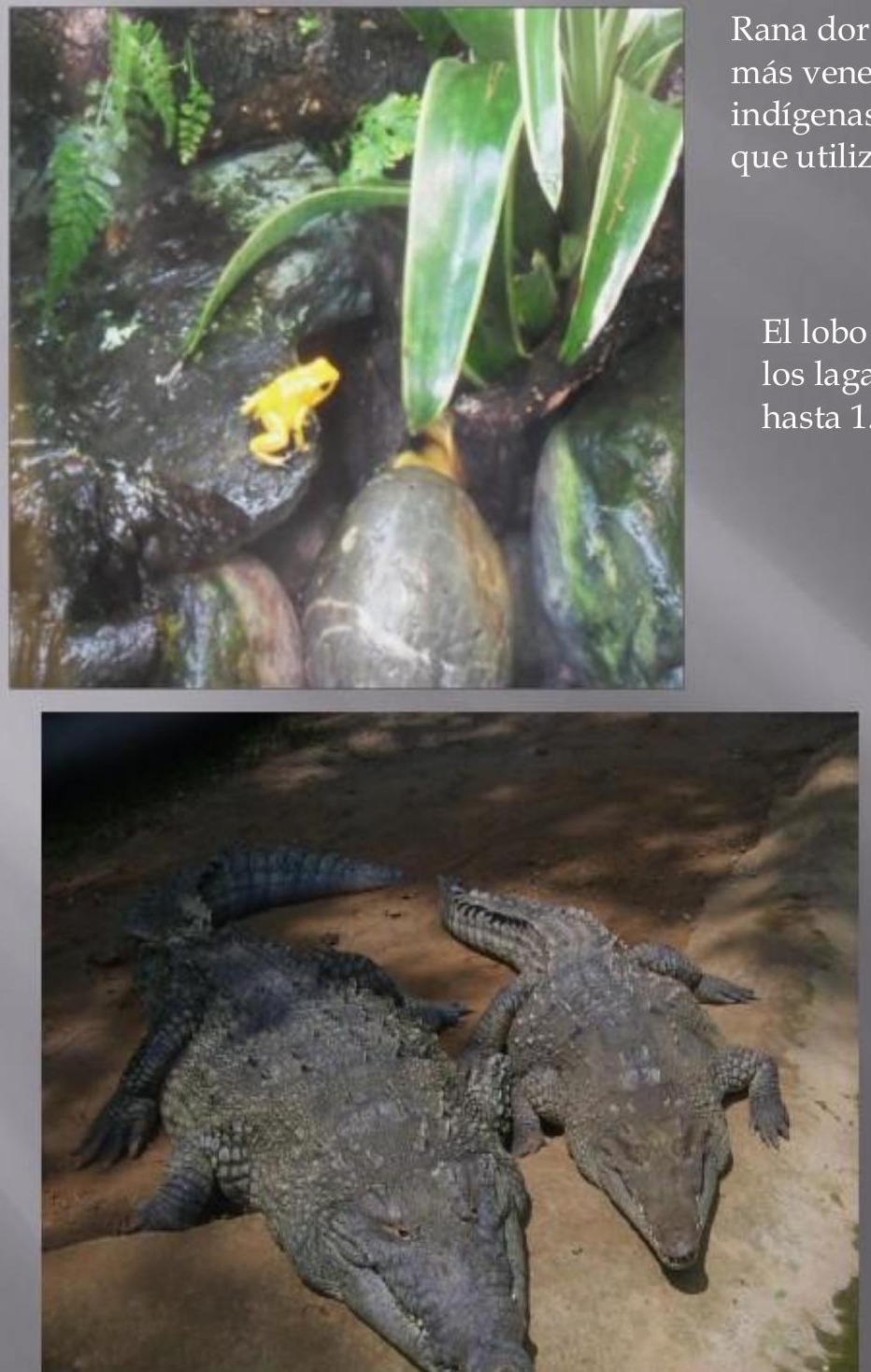

Rana dorada (Phyllobates terribilis) una de las especies más venenosas del mundo, es utilizada por los indígenas de la Amazonia para envenenar los dardos que utilizan en la caza.

El lobo pollero o Caripiari (Tupinambis teguixin) es uno de los lagartos más grandes del planeta, puede llegar a medir hasta 1.5 metros y es originario de Sur América.
El Cocodrilo del magdalena (Crocodylus acutus) es una de las especies de cocodrilo mas grandes del planeta. 


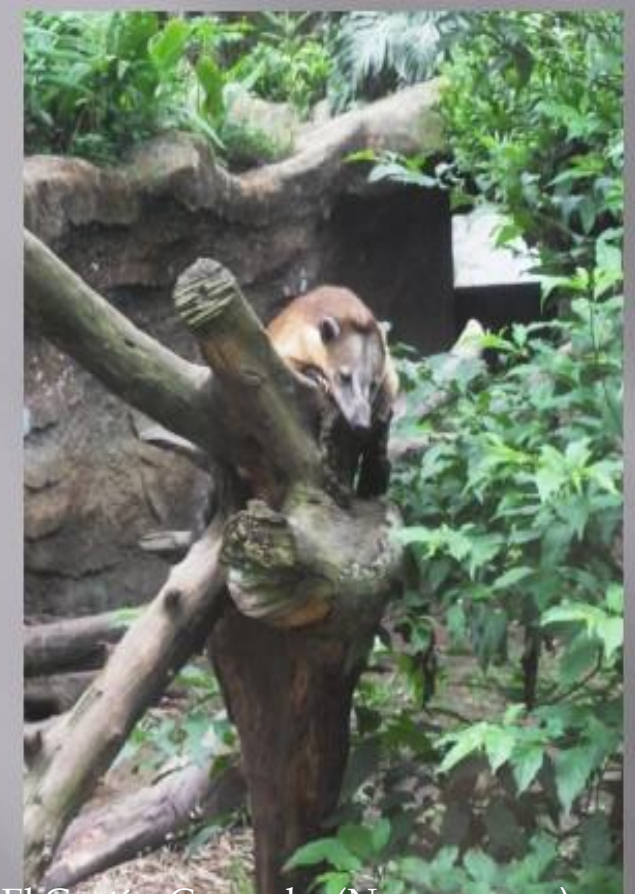

Eleoat o Cusumbo (Nasua nasua) es una de la especies que se encuentra én grave peligro debido a su fácil domesticación ha sido considerado por muchos humanos como mascota.

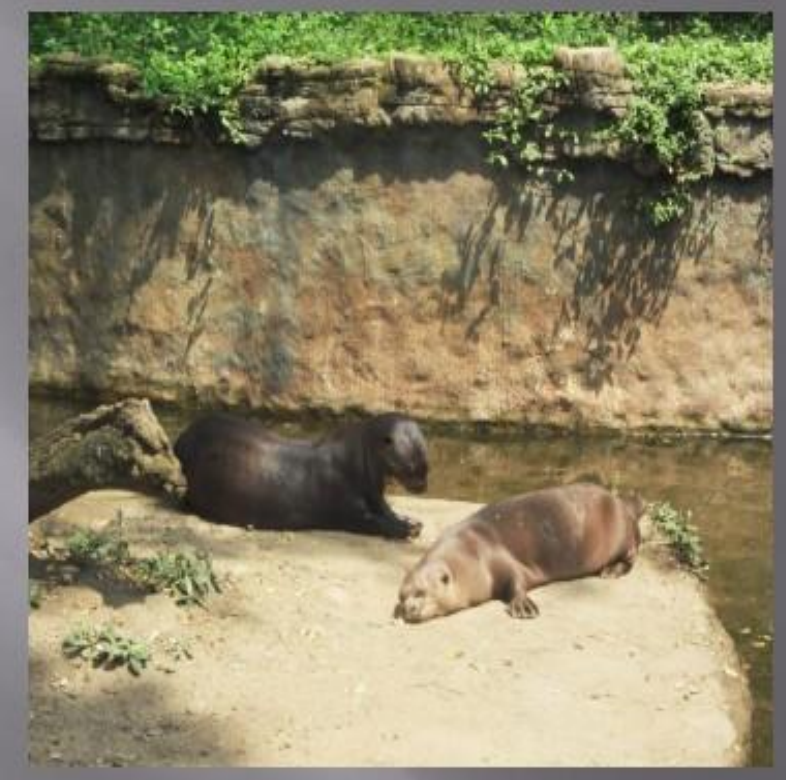

La nutria gigante de rio (Pteronora brasiliensis) es una de las especies bandera del zoológico, su reproducciónen cautiverio ha sido exitosa, varios de estos individuos se han enviado a otros zoológicos del continente o han sido introducidos a su ambiente natural.

Chiguiro o Capibara (Hydrochaeris hydrochaeris) es el roedor mas grande del mundo. Es muy territorial y de comportamiento social.

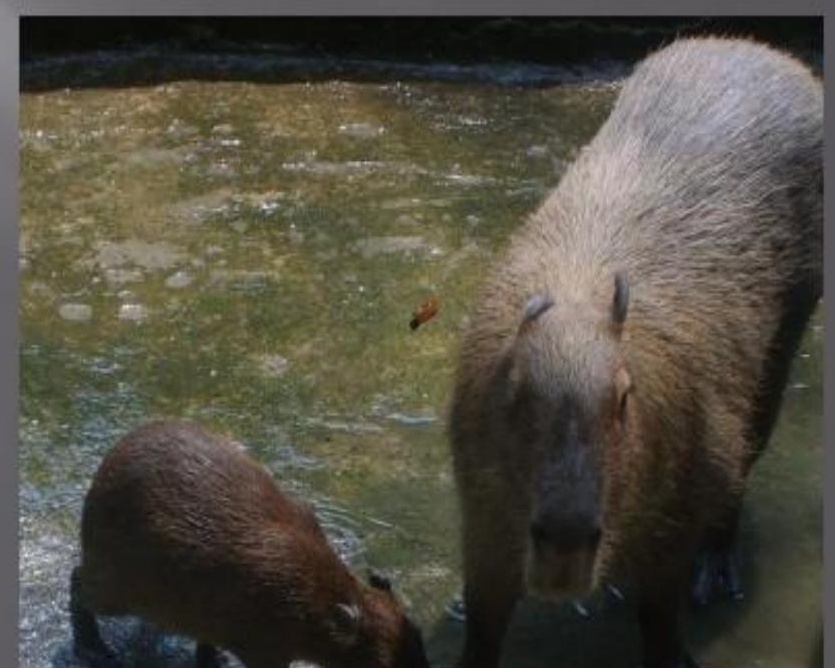




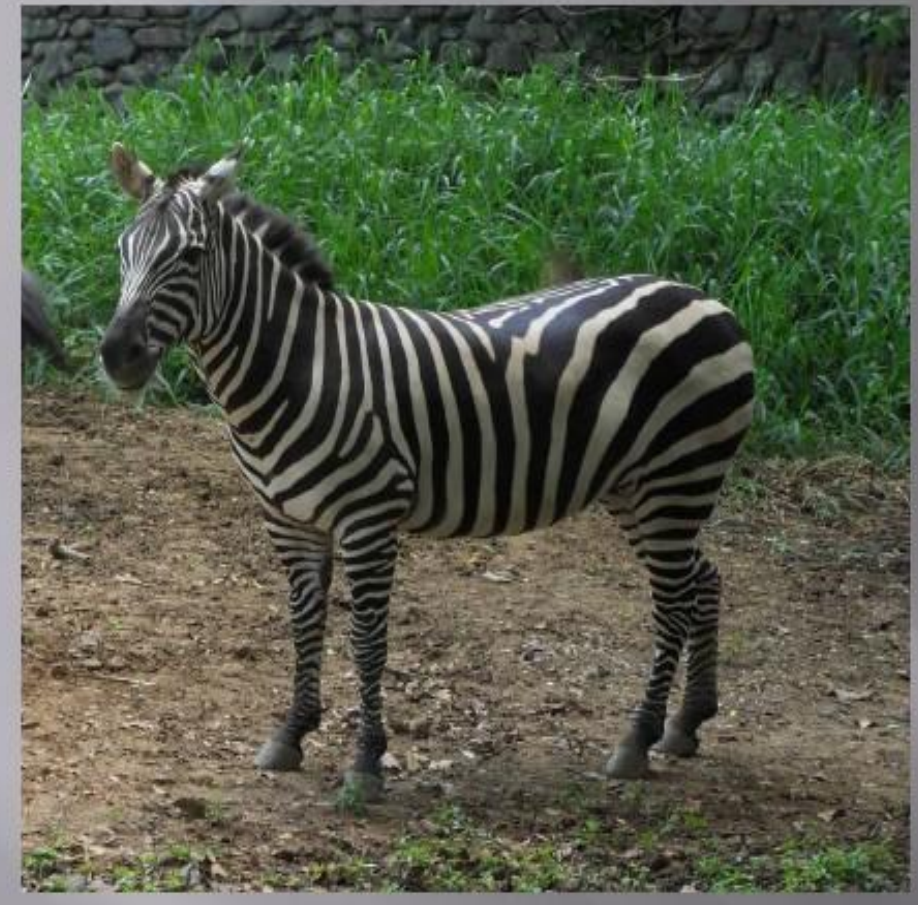

Los Suricatos (Suricata suricatta) son bastante agradables al publico, debido a que son bastante activos además quien no recuerda a Timón el amigo incondicional del Jabalí en la película El rey León.
Cebra común (Eqqus burcheli) vive en las sabanas Africanas, el patrón de sus rayas es diferente en cada uno de los individuos.

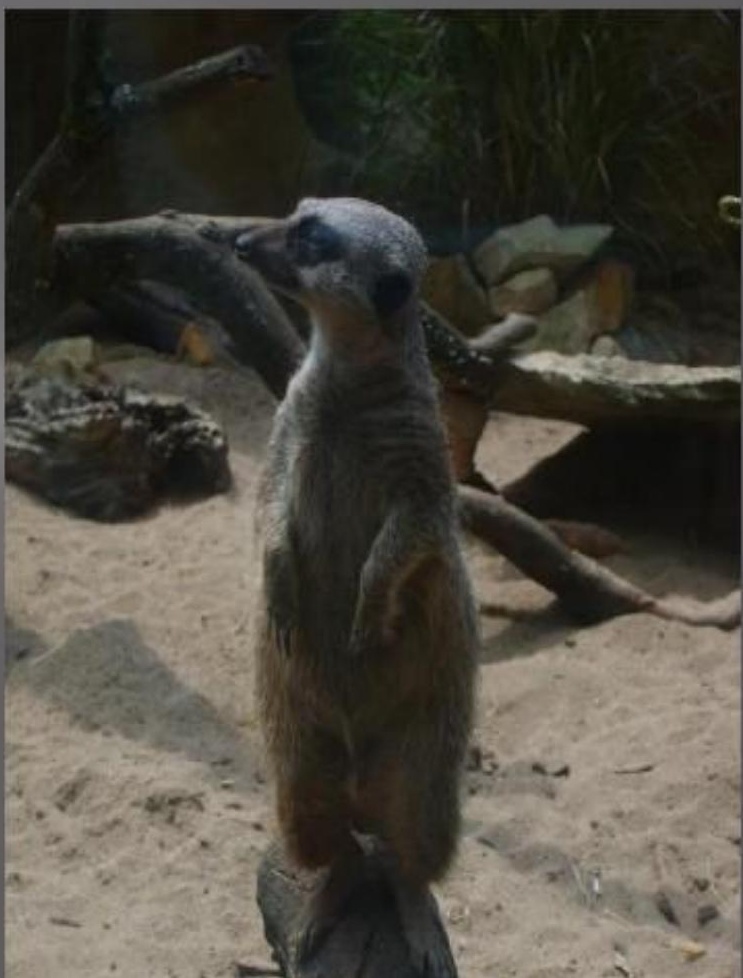

